\title{
Literary Texts and Direct Speech Representation: Explorations in the Discoursal Values of Direct Quotation as a Textual Strategy
}

\author{
Mina Abbassi Bonabi \\ Payam-e-noor University, Iran \\ Email: mina_abbasi89@yahoo.com \\ Manoochehr Jafarigohar \\ Payam-e-Noor University, Iran \\ Email: jafarigohar2007@yahoo.com
}

\begin{abstract}
Direct quotation as a textual strategy has different functions in different text-types. In informationoriented text-types, such as scientific texts, one of the most prominent functions of direct quotations is their contribution to the enhancement of the information load of the text. That is to say, direct quotations in the information - oriented text- type contribute to the 'ideational meaning' of the text. In more speaker - oriented and subjective texts, such as advertisements and journalistic texts, direct quotations mostly contribute to the 'textual meaning' of the text. Defining direct quotations as a textual strategy and believing that this strategy adds different dimensions of meaning to the semantic realm of a text in different text-types, in this paper the attempt is to see what dimensions of meaning are added to literary texts through using direct quotations and explore the discoursal values of this textual strategy in the literary text-type. For this purpose three literature texts (one short story and 2 poems) were chosen to be analyzed in terms of the presence of direct quotations in the texts with some speculations on their discoursal functions. We found out that direct quotations are 'thematically motivated' elements in literature texts, reinforcing the theme of the text and creating aesthetic effect in such texts. On the basis of the findings of our present study, we suggest that there are no generic conventions determining the presence or absence of this textual strategy in different text-types. However, this textual strategy has different functions in different text-types and these values are governed and determined by the communicative intention and attitude of the producer of the text as well the meta function or the overall function of the text-type to which the text belongs.
\end{abstract}

Index Terms - host text, pretext, intertextual strategy, textual strategy, discoursal values, meta function

\section{INTRODUCTION}

Regarding 'direct speech representation' or 'direct quotation' as a textual strategy, this paper attempts to investigate the cognitive effects and discoursal values of this strategy in literature texts. We want to discover why the producer of a literary text resorts to this textual strategy rather than other textual strategies (i.e. indirect speech representation) to convey his intended massages and explore its effects in widening the scope of meaning potential of literature texts. Believing that language is not an indifferent presenter of the underlying meaning and also believing that the mode of presentation or way of saying something affects the meaning to be negotiated, the paper attempts to look at 'direct speech representation' as a textual strategy trying to justify its presence in literature texts in the light of the underlying discoursal motivations. Using Halliday's Systemic Functional Linguistics as framework of text analysis, and believing that there is no free variation in terms of the presence of textual strategies used in a text and also considering the fact that any change in way of saying is a change in the meaning to be negotiated through the text, in this paper we look at direct quotation as a textual strategy trying to explore its values in literature texts in the light some underlying discoursal motivations. It is of special interest to find out why the writer of a literature text uses 'direct speech representation' rather than another textual strategy, for example indirect speech representation, to convey his intended massages in a specific text and explore how the use of this textual strategy produces 'aesthetic effect' in literature texts. We believe that in literature the use of 'indirect speech representation' instead of 'direct speech representation' could not produce the same literary effect because in literature the way of saying something is as important as what is said (see Lotfipour, 1989). For this purpose three literary texts are chosen to be analyzed in terms of presence of direct quotations trying to explore their values in creating literary effect.

\section{DiRECT SPEECh REPRESENTATION AS AN INTERTEXTUAL STRATEGY}

We define direct quotations as an intertextual strategy because the producer of a text by bringing the wording of some other writer into the universe of his own text initiates intertextual relations between the two texts. But we should 
notice that intertextuality can be created by other means such as using metaphor in the text. We should also consider the fact that the sole purpose of the direct quotation is not restricted to the creation of intertextuality. Indeed, as it will be mentioned below, direct quotation is a strategy which contributes to fulfill various functions both within a text and across different text-types.

\section{A. Different Modes of Intertextuality}

We believe that intertextual strategies can be realized in various modes in a text. The various modes of intertextuality establish various kinds of relation between a text and semantic realms of other semiotic systems. That is to say the nature of the intertextual relation established between a text and other semiotic universes through one mode of intertextuality such as quotation is different from the nature of the intertextual relation established through another mode of intertextuality such as metaphor. Generally speaking the intertextual relations between a text and semantic universes of other texts can be established at different levels and it is through the different modes of intertextuality that such different relations are created. One type of relation between a text and other texts is the relation established at the level of wording. This kind of relation (i.e. the relation at the level of wording) is mainly and basically established through a particular mode of intertextuality that is 'direct speech representation' or 'direct quotation'. Direct quotations as one mode of intertextuality create links between a text and other texts through representing the exact wording of one text (we call it pretext) in another text (we call it host text). Metaphor as another mode of intertextuality establishes the link between a host text and other texts at the semantic level through bringing some guest images into the host texts from other semantic realms. The relation between the host text and other texts can be established at the other level called pragmatic level. The links between texts are established at the pragmatic level when the local text and other texts contribute to fulfill the same function in the society or when the texts have the same topic or theme (see Lemke, 1985).

We have already investigated the cognitive and communicative effects of 'direct speech representation' in three different genres of scientific, journalistic and advertisement texts (see Lotfipour \& Abbasi, 2000 - 2001). Defining 'direct speech representation' or 'direct quotation' as an intertextual strategy linking a text to other text(s), we investigated the textual variations of this strategy in the scientific, journalistic and advertisement texts and tried to justify the variations in the light of the underlying discoursal motivations. We found out that different dimensions of meaning are added to the semantic realm of the texts through the use of this textual/ intertextual strategy.

The motivation behind Lotfipour \& Abbasi's study was that authors were interested to find out why and how the producer of a text consciously and intentionally brings the exact wordings of another person into universe of his own text and how this strategy is manifested in different text-types and what dimensions of meaning are added through the use of this strategy in different text-types. The study revealed interesting findings. They found out that there are no generic conventions determining the way of textual manifestation of 'direct speech representation' or 'direct quotation' in different text-types. Rather it is the communicative intention and attitude of the discourser producer vis-a- vis the topic of the text as well as the meta- function of the text-type to which the text belongs which determine the discoursal values of this strategy in different texts. The above - mentioned study also revealed that 'direct speech representation' is not a uni- functional strategy but in any text belonging to any text-type, this strategy may fulfill several functions simultaneously.

As it was mentioned above, the dominant discoursal functions of this strategy in any text are determined by the metafunction of the text-type. For example in the scientific text-type which is information oriented text-type, Lotfipour \& Abbasi (2000-20001) found out that 'direct speech representations' generally contribute to ideational function of the text whereas in the journalistic texts the most dominant function of this strategy is to contribute to the textual function of indirectness. They also found out that in advertisements 'direct speeches' or 'direct quotations', by violating the Gricean maxim of relevance, contribute to the general function of this text-type which is getting the attention of readers.

As it was mentioned above, Lotfipour \&Abbasi (2000-2001) defined 'direct speech representation' as one mode of intertextuality and attempted to look at different dimensions of textual variations of this mode of intertextuality in different texts. They tried to find out the underlying communicative and cognitive values of this strategy in different texts. One dimension of variation in textualization of this intertextual strategy is variations in rank dimension. They found out that in the scientific text-type the direct quotations below the clause rank (i.e. words and noun phrases) can be considered as core elements because they contain new information and have a high degree of necessity for the unfolding of the host text. The authors argued that the producer of the scientific texts by bringing direct quotations below the clause rank and rendering them as guest elements in the scientific host texts increases the information load of the texts as well as increasing the degree of recalliability and comprehensibility of the texts. This is because the textual contrast created by paralinguistic features (i.e. quotation marks) makes the new elements more prominent and hence forces the reader to focus upon them and this boosts the degree of comprehensibility and recalliability of the scientific texts. As far as direct quotations above clause rank are concerned, Lotfipour \& Abbasi (2000-2001) argued that in the scientific texts, the most frequent direct quotation is texts. They pointed that the degree of necessity of direct quotation in the form of texts for the scientific host texts is in a lower level compared with direct quotations in the form of words and noun phrases. This is because that the information contained in guest texts was found to be redundant to the host texts. They argued that by bringing in direct quotations in the text rank, the producer of a scientific text can compensate for his imperfect gauge of the background knowledge of his readers. In the scientific text -type, the guest texts, while fulfilling 'reiteration strategy' (2) and hence increasing the comprehensibility of the text for some readers, seem to be added to 
the host text to increase the accountability and reliability of the texts for some other readers. So we notice that 'direct quotations' in a text have various functions for different readers. We can also argue that the general functions of direct quotation are determined by the meta function of the text-type to which the host text belongs. In the scientific texts which are reader oriented with a high degree of objectivity, 'direct quotations' appear in the texts to increase the relative objectivity of texts in reflecting the outside reality.

As far as journalistic text-type is concerned, Lotfipour \& Abbasi (2000-2001) found out that the most frequent 'direct quotations' are elements in sentence rank. They argued that there is no guarantee that the direct quotations in sentence rank appearing in a journalistic host text increase the truthfulness and reliability of the host text. This is because what is transferred to the host text is the propositional meaning of the sentences not their illocutionary force. So the presence of guest sentences in a journalistic host text rather than reflecting the communicative intention of the producer of the original text from which the guest sentences have been taken, contributes to the communicative intention of the producer of the host text. Among other functions of 'direct quotations' in a journalistic text, we can mention that direct quotations in sentence rank contribute to discoursal function of indirectness. By adding guest sentences to the journalistic host text and by special arrangement of them in the textual hierarchy of the host text, the writer can express something which he cannot express directly with his own words (see, Lotfipour \& Abbasi, 2000-2001). In speaker oriented subjective texts, such as journalistic texts, the dominant discoursal values of direct quotations are by no means to add any dimensions of accountability and truthfulness to the text. Direct quotation in this text-type can be used to create and construct realities rather than reflecting the outside objective reality.

Lotfipour \& Abbasi (2000-2001) argued that in advertisements most of the direct quotations are completely irrelevant to the subject matter of the host text at the semantic level. They found out that there is no direct or implied relation between the direct quotations and the message of the host text. The degree of necessity of the direct quotations for the unfolding of the text is approximately zero. The Gricean maxim of relevance is violated in most cases in this text-type. The act of violation of the semantic relevance between the direct quotations and the topic of the host text is strategic to attract the attention of the readers (see, Lotfipour \& Abbasi, 2000-2001).

We summarize this section by reiterating the postulation that it is the meta function of a text and the communicative intention of the writer of the text which determine the cognitive and communicative effect of 'direct equations' in different texts. In objective, reader- oriented texts such as scientific texts, direct quotations are added to increase the reliability of the text. In addition to this generally accepted function, direct quotations have also other functions such increasing comprehensibility and fulfilling reiteration strategies. In subjective and speaker - oriented texts, direct quotations contribute to the textual meaning of the text.

The aim of the present paper is to find out the discoursal values of direct quotation as a textual strategy in literature texts. We speculate that the values of direct quotations in literature texts are determined by the overall functions of literary texts. Like other literary devices, this specific device is strategically used in literature text to produce 'aesthetic effect'.

\section{B. Literary Texts and Direct Speech Representation}

As it was mentioned above, the aim of this paper is to look at the nature of literature-texts, focusing especially on how the writer of a literature-text employs Direct Speech Representation as a textual / intertextual strategy to create 'literary effect'. We want here to examine the postulation that using 'direct quotation' in a literary-text is a way of 'special patterning of language patterns' (Hasan, 1985), contributing to the literariness of a text.

By 'direct speech representation' or 'direct quotation', as it was mentioned above, it is meant taking the 'exact wording' from a text (pretext) and representation them in another text (host text). So we have defined it as an intertextual strategy linking an already existing text to a host text. It should be noticed that there is a distinction between literature and noun-literature, in terms of the nature of pretexts. In non- literature, the guest elements are taken from the specific, really existing, original texts (i.e. pretexts) (Waugh, 1995), but in literature, direct speeches are not usually taken from any really existing, original texts. They are mainly taken from imaginary texts. So the function of direct speeches in literature is not at all to add any dimension to the factuality, accountability or reliability of the host text. The dimension of meaning added to the literature-text through employing this strategy (i.e. bringing the direct speeches to the universe of the host text) is different from the dimension added through this strategy to non- literature. We believe that this mode of guest elements in literature is a 'foregrounding' contributing to the literary effect of a literature-text. It is the concern of this paper to shed some light on how 'direct quotations' in literature become foregrounding and how the producer of literature texts employs them strategically to produce 'aesthetic effect'.

Some stylisticians, in an attempt to characterize the nature of literature-texts, have tried of define the nature of literature-text in terms of the formal features or 'special patterns' of language. But this way of characterization of literature meets draw back. New finding on genre analysis reveal that different text-type are not distinct from one another in terms of presence of different linguistic resources in different text-types. Short (1991) argues that literature and other forms of language are not obviously distinct in terms of their linguistic ingredients. That is to say, the producer of a literature-text in creating his text employs the same linguistic resources that a writer of, let say, a scientific text uses them in producing his text. The difference between literature and non- literature is not in 'what is used' but in 'how something is used'. It is the values of some patterns rather than the mere presence of that patterns which produce literariness of literary texts. 


\section{The analysis of Eveline}

The first literary text chosen to be analyzed is a short story by James Joyce: Eveline. An attempt will be made to examine some of the direct quotations used in the text to explore their value in the text and also to examine how these elements can be regarded as 'foregrounded' contributing to literariness of the text.

The fiction portrays a human being great suffering created through a contradiction between her 'legitimate human desires' (3) to have happiness and love, to have somebody to protect her, to give her life on the one hand and her duty and commitment and her promise 'to keep the home together', to protect her helpless family and help her father who 'was becoming old lately' on the other hand. At home, of course, she had a hard life; 'she had to work hard both in the house and at business' she sometimes 'felt herself in danger of her father's violence'. But Frank, her boy friend, was 'very kind and manly and open hearted'. He had a home in Buines Ayres 'waiting for her'. The girl has two roads before her to choose: she may go away with Frank, leave her home or she may continue to live with her family, keep her promise to her dead mother. The girl felt great suffering in understanding the right way to go. She prayed to God to direct her, to show her what her duty was. And lastly she decided to sacrifice her 'legitimate human desires', her love and her life for the sake of her unprivileged family. And it is a tragedy, a tragedy of a human being whose fate compelled her to sacrifice herself when she found a conflict between her love and her duty. But her fate had not been determined by 'astral determinism' (see Ryan; 1991). Her fate was determined by other human beings who exploited other people and deprived them from their legitimate rights. Eveline's family, like herself, was a victim of injustices existing in the society.

After presenting a brief account of the story we attempt to look at some direct quotations used in the story. In our analyzed fiction-prose: Eveline, all direct quotations are sentences which are actualized in the textualization process as independent paragraphs.

The first direct quotation to be focused here is realized as the fourth paragraph of the text. In the paragraph 3 the pretext is established:

Pretext:

<whenever he showed the photograph to a visitor, her father used to pass it with causal word :>

Direct Quotation

$<<\mathrm{He}$ is in Melbourne now. $>>$

Here we believe that the direct quotation is a 'foregrounded element' of the story. It is foregrounded because it is in contrast with its background in terms of the selection of tenses (see Hasan, 1985). All other verbs in the host text are either in simple perfect or perfect past tenses (see Behin, 1991). The occurrence of simple present tense in the direct quotation creates a contrast between the element and its background; and this contrast gives foregrounding to the direct quotation. The occurrence of simple present tense in the direct quotation is "thematically motivated". According to Hasan (1985) simple present tense signifies unvarying routine which leads to predictions. The theme of the fiction is predictable fate of girl who scarified her life for the sake of her family. Even the average reader of the fiction, before coming to the end of the story, would predict that the girl would not leave her family. This predictability is reflected in tense selection of the foregrounded part of the text (i.e. the direct quotation). The contrast between tense selections and resulting foregrounding would not have occurred if the writer had used indirect speech representation, because in that case he had to use simple past tense instead of simple present tense. The use of present tense in the foregrounded element here is thematically motivated.

Consider transitivity structure of the direct quotation

\begin{tabular}{|l|l|l|}
\hline $\mathrm{He}$ & Table \#1 & in Melbourne now \\
\hline Carrier & is & Attribute \\
\hline
\end{tabular}

Hasan (1985) introducing the notion of 'effectuality'- or dynamism and defining it as the quality of being able to affect the world around us, and of bringing change into the surrounding environment, says that 'the least dynamic role is that of carrier'. Considering dynamism as a continuum, she regards dynamic as one end of the continuum, the other end point of which would be 'passive'. According to Hasan (1985) the most dynamic role is carried by Actor $\wedge$ Process :Material ^ Goal especially when the Goal is a human being. Consider this example:

Dick sent Tom away.

Here Dick is considered to have a high degree of 'effectuality' being able to change the surrounding. According to Hasan's formulation in the transitivity structure of Carrier ${ }^{\wedge}$ Process $^{\wedge}$ Attribute, the carrier has a passive role having no or very little capacity to change the surrounding environment. As table 1 illustrates the direct quotation has this transitivity structure. The use of this structure is also thematically motivated. The concern of the story is to show that the unprivileged people of this story cannot determine their fate; they cannot affect the world around them and cannot bring any change to their lives. If the writer had used this sentence: He lives in Melbourne now instead of the above quotation, he could not have produced the literary effect.

The second direct quotation we want to discuss is realized as paragraph 15. In paragraph 14 the pretext is established. The girl, still in the state of hesitation, heard a 'street organ playing' played by an Italian player. It reminds her of the last night of her mother' illness and also of her promise to her dead mother to keep the home together. At that night, the 
street organ playing had been heard. The organ player had been ordered to go away. It was that night when her father had said:

Damned Italians! Coming over here

This direct quotation here functions as an intertextual element which links the girl's present situation to the last night of her mother's illness is again a foregrounded element being in contrast with the consistent background both in tense selection and style. The tense of the G-elements is present in contrast to past tense of background. The style of the direct quotation is informal spoken language in contrast with the literary language of the text.

Consider the transitivity structure of the G-elements:

\begin{tabular}{|l|l|l|l|}
\hline Damned Italians! & \multicolumn{2}{|l|}{} & \multicolumn{2}{|l|}{ Coming over here } \\
\hline & Subject (elliptical) & Finite (elliptical) & \multicolumn{2}{l|}{ Residue } \\
\hline & Actor: (elliptical) & Process: Material & Attribute \\
\hline
\end{tabular}

The elliptical nature of the direct quotation shows that it is in the spoken language. From tranivity structure: Actor ${ }^{\wedge}$ process: Material ${ }^{\wedge}$ Attribute

The Italians are the Actor of the Material process. Referring to Hasan' formulation (1985), we suggest that the effectuality of this sentence is higher than the sentences which have Relational or Mental process.

The relative high degree of effectuality of Italians as the Actors of a Material process, illustrates the more dynamic role of Italians in changing their surrounding conditions. Italians have immigrated. They have tried to change their situations. But nobody likes them: 'Damned Italians'. Their action is condemned. Eveline's father had ordered them to go away. Nobody wants them. It symbolically shows that nobody wants changes. So Eveline should not go away. The Italians' attempts in changing their conditions are condemned. So she should remain with her family. The sound of organ playing also reminds her, of her promise to keep the home together. So Eveline would not leave home.

\section{The AnAlysis of Two PoEms}

The second text that we will attempt to analyze in terms of its direct quotations is a poem written by Alfred, Lord Tennyson:

\section{HOME THEY BROUGHT HER WARRIOR DEAD}

Home they brought her warrior dead,

She nor swooned nor uttered cry.

All her maidens, watching, said,

"she must weep or she will die."

Then they praised him, soft and low,

Called him worthy to be loved,

Trust friend and noblest foe;

Yet she neither spoke nor moved.

Stole a maiden from her place,

Lightly to the warrior stepped,

Took the face-cloth from the face;

Yet she neither moved nor wept.

Rose a nurse of ninety years,

Set his child upon her knee-

Link summer tempest came her tears-

" Sweet my child, I live for there".

In this poem, there are two guest-elements in the mode of 'direct speech representation'. The elements are realized in the sentence Rank, so they are guest sentences. We believe that the direct quotations here are 'foregrounded' elements of the poem.

The first direct quotation:

$<<$ She must weep, or she will die>>

The sentence is foregrounded here firstly through its selection of tense. The tense of the guest sentence is future which is in contrast with its 'consistent background'. The tense of verbs of the background are in simple past tense from. Here the future tense of the verbs of the guest sentence foregrounds the sentence against its background.

The theme of the poem is the extraordinary depth of a woman's love for her husband who is now dead. The woman is prepared to die rather than face life without her warrior. Being alive she should undergo 'the torment of separation' (see Ryan, 1991) which she can never tolerate. She can find unity with him through death. Weeping is the sign of accepting his separation. So she 'neither moved nor wept' in spite of her maidens' attempts to force her to weep. The woman', like Evelin', has two roads before her to choose. She can refuse weeping and as a result she can choose death, 'to go 
away', to find unity with her love, or she can weep and continue to live with the great torment of being separated from her love. She has two ways: << she must weep, or she will die>>. In the direct quotation, both verbs: " weep" and "die" are modified by a modal. The process 'weep' is modified by the modal must, while the process 'die' is modified by will. The modal must expresses a high degree of necessity and obligation. The actor has no other choice rather than doing the verb which is modified by the modal must. But the modal 'will' expresses willingness and freedom to do something rather than expressing necessity or obligation. Again we see the selection of processes and modals in the foregrounded sentences is 'thematically motivated'. The theme of the poem is that the woman in spite of her deep willingness and preparation to be united with her love through her death is obliged and forced to be alive. She must weep unless she will die.

And her tears come like 'summer tempest' (line 15). Tempest in the summer is an undesirable event and her tears like a summer tempest are undesirable, leading to her separation from her love. But ...

The second direct quotation:

$<<$ Sweet my child. I live for thee >>

Here again the direct quotation is foregrounded against its consistent background through the contrast created by tense selection between the sentence appearing in the direct quotation (the foregrounded element) and its background. While the consistent tense of the verbs of the background is past tense, the sentence appearing in the direct quotation is foregrounded by the presence of simple past tense within it. Again referring to Hasan (1985), we mention that the normal function of present tense is to indicate the presence of routine which forms a basis for predictions. In this poem the predictability of the human beings' nature to sacrifice its greatest concern, that is love, to perform its duty is dramatized.

If the woman instead of saying: "Sweet my child, I live for thee" had said: "Sweet my child, I will live for thee", her effectuality and dynamic role as the Actor of a Material process would have increased. But this lower level of effectuality of the woman is 'thematically motivated'. The main concern of the poem, that is to say its theme is to illuminate how some 'human conditions' cannot be challenged by human beings. The duty of mother to protect her helpless child is determined by human conditions and any refusal and evading of it is considered to be a moral defect. So the mother in this poem has no other choice rather than protecting her child even though it causes her to tolerate the torment of separation of her lover.

The themes of the fiction Eveline and this poem are the same: sacrificing love for performing duty. But when the duty of the woman in the poem is determined by human conditions and cannot be challenged, the duty of Eveline to protect her unfortunate family is not determined by 'human conditions'. The misery of the family is created by poverty deriving from injustices in the society, and these injustices should be challenged.

In sum in literature-text, direct quotations are foregrounded elements because they are not only prominent textual features of the text but also they are thematically motivated. The degree of necessity of direct quotations to a literary text is very high because there are underlying thematically motivated links between the linguistic forms appearing in the direct quotations and the theme of the literary text. To illustrate the strong links between the direct quotations within a literary text and its theme, notice the following poem:

\section{THE MILL}

The miller's wife had waited long,

The tea was cold, the fire was dead;

And there might yet be nothing wrong

In how he went and what he said:

"There are no millers any more,"

Was all that she heard him say;

And he had lingered at the door

So long it seemed like yesterday.

Sick with a fear that had no form

She knew that she was there at last;

And in the mill there was a warm

And mealy fragrance of the past.

What else there was would only seem

To say again what he had meant;

And what was hanging from a beam

Would not have heeded where she went.

And if she thought it followed her,

She may have reasoned in the dark

That one way of the few there were

Would hide her and would leave no mark: 


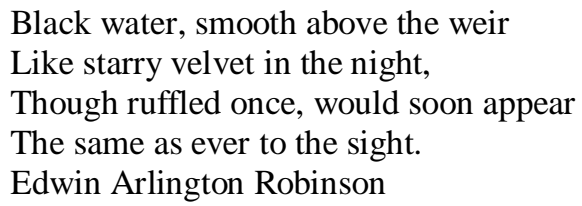

The poem was written in the context of Industrial Revolution where many people lost their jobs into machinery and in that context the loss of livelihood meant death for many people. In this poem death is symbolically dramatized through many images such as: cold tea, dead fire, black water etc. The theme of the poem is the death of people following the death of their livelihood. The direct quotation of the poem is:

$<<$ There are no millers any more >>

Here we see that the theme of the poem is clearly stated in this direct quotation. The direct quotation is forgrounded element of the poem because it is referred within the text several times in lies 4-5 and 14. The direct quotation here is a device to repeat and reiterate the theme of the poem and again we see that the direct quotation in this literary text is a thematically motivated element contributing to produce the literary and aesthetic effect of the text.

\section{SUMMARY AND CONCLUSION}

Through the analysis of some literary texts in terms of presence of direct quotations, in this paper we tried to illustrate that the value of any linguistic form or any textual strategy in literature texts is determined by the overall function or meta function of the literature texts. The textual strategies employed in literary texts gains their significance by directly or indirectly reinforcing the underlying theme of the texts. In literature texts all linguistic devices act harmonically to reinforce the underlying theme of the texts to produce aesthetic effect. It should be noticed that there are no predetermined functions for any linguistic devices in literature texts. The values and discoursal functions of any textual strategy within a text, direct quotation included, are unique to that text. Another point which needs to be reiterated here is that 'direct quotations' in any text type, literary texts included, may appear to fulfill different functions simultaneously. But the prominent function of a direct quotation in any text is determined by the overall function or the metafunctions of the text-type to which the text belongs.

Notes:

1- By pretext it is meant any actual or imaginary text from which a direct quotation is taken. By host text we mean the text into which the quotation is inserted. Meta function in this paper means the overall function or general function of a genre, for example the meta function of the scientific text-type is conveying information.

2- By reiteration strategy we mean the strategies employed by the producer of a text to compensate for any cognitive limitation on the part of the reader. Reiteration strategy can be variously manifested in textualization process. The function of this strategy is to reactivate and reiterate the previously presented information through repetition to compensate for any cognitive limitation on the part of the reader (see Lotfipour, 1992).

3- In the analysis of Fiction Eveline some insights have been taken from Ryan (1991).

\section{REFERENCES}

[1] Behin B. (1991). A Systemic Functional Approach to Analysis of Fiction - Prose: Implication for Translation Equivalence in Literature. Unpublished M.A. Project', University of Tabriz Iran'.

[2] Birch, D. (1991). Language, literature and critical practice, Routledge. 11 New Fetter Lane, London.

[3] Butt, D. (1988). 'Ideational meaning and existential fabric of a poem' in Fawcett, R.P. \& Young D. J. (eds.) New Developments in Systemic Linguistics Vol. 2 Theory and Applications. Printer Publishers. Pp. 174-218. London.

[4] Candlin, C. and Lotfipour- Saedi, k. (1983). 'Processes of discourse'. Journal of Applied Language Studies 1(2), $103-310$.

[5] Deming, Robert, H. (1986). `Theorizing, Textuality, Intertextuality`. Journal of communication Inquiry 10/3 pp.32-44.

[6] Fairclough, N. (1990). Language and power, London. Longman

[7] Fairclough, N. (2010). Critical Discourse Analysis, Longman UK.

[8] Fowler, R. (1985) 'Power` in van Dijk (ed.) Handbook of Discourse analysis, New York: Academic press.

[9] Fairclough, N. (2010). Critical Discourse Analysis, Longman UK.

[10] Halliday, M.A.K (1973). Exploration in the function of language, London: Edward Arnold.

[11] Halliday, M.A.K. (1978). Language as social semiotics: the social interpretation of language and meaning. Edward Arnold, London

[12] Halliday, M.A.K. (1985). An introduction to Functional Grammar, London: Edward Arnold.

[13] Halliday` M.A.K \& Hasan` R. (1976). 'Cohesion in English` London: Longman.

[14] Halliday M.A.K. Hasan` R. (1990). Language, Context and Text: Aspects of Language in a Social Semiotic Perspective` Oxford university Press. Oxford

[15] Hassan, R. (1985). Linguistics, language and Verbal Art. Victoria: Deakin University Press.

[16] Lemke, Jay L. (1985). 'Ideology, Intertextuality and the Notion of Register' in James D. Benson\& William S. Greaves (eds.) Systemic Perspective on Discourse. Vol. 1 Selected Theoretical Papers from the $9^{\text {th }}$ International Systemic Workshop. Norwood, N.5: Albex Publishing P. 275-294.

[17] Lotfipour- Saedi, K. (1989). `Analyzing Literary discourse: Implication for literary translation.`A paper presented at the first Tabriz University Conference on translation. Iran Tabriz University. 
[18] Lotfipour -Saedi, K (1992). 'Variation in Textual Strategies and their Pscho-Sociological Motivations'. A paper presented at XVth International Congress of Linguistics (CIL. 92), University of Laval Quebec City, Canada.

[19] Lotfipour, Saedi, K. \& Abbasi Bonabi M. (2000). 'Intertextuality as a Textual Strategy: Explorations in its Modes \& Functions' Iranian Journal of Applied Linguistics. Vol.4 No. 2 pp: 79-112.

[20] Lotfipour -Saedi, K. \& Abbasi Bonabi M. (2001). 'Intertextuality as a Textual Strategy: Explorations in its Modes \& Functions' Iranian Journal of Applied Linguistics. Vol.5 No.1 pp. 36-54.

[21] Lotfipour -Saedi, K (2006). On Discoursal Function of Some Special Textual Strategies in Poetic Texts: Implication for Literary Translation in Meta 51-3 p. 545-550

[22] Ryan, K. (1991). Romeo and Juliet: the language of tragedy' In Willie van Peer (ed.) The Taming of the Text, Routledge. London.

[23] Short M. (1991). 'Speech presentation, the novel and the press` The Taming of the Text, Routledge. London.

[24] Waugh, Linda R. (1995). 'Reported speech in journalistic discourse: the relation of function and text' in Text 15(1) p. 129-173.

Mina Abbassi Bonabi got her M.A. on Applied Linguistics from Tabriz University in 1996. Her M.A. thesis was on intertextuality entitled: Intertextuality: Exploration in its functions and modes. She is now a PhD candidate at Tehran Pyam-e- noor University, Iran. Her research interest is on genre analysis, critical linguistics and discourse analysis.

Manoochehr Jafarigohar: Ph.D. in TEFL, MA in TEFL, BA in English translation; author of thirteen academic textbooks; presentation in more than 20 international conferences; published papers in various journals; 25 year experience of teaching English; 20 years of teaching and research in distance education; advisor and reader to over 100 post-graduate theses and dissertations 